\title{
RACK1 promotes miR-302b/c/d-3p expression and inhibits CCNO expression to induce cell apoptosis in cervical squamous cell carcinoma
}

\author{
Jing Wang and Shengcai Chen*
}

\begin{abstract}
Background: Cervical squamous cell carcinoma (CSCC) is one of the main causes of cancer-related deaths in women worldwide. The present study was conducted with the main objective of determining the potential role of receptor for activated protein kinase C1 (RACK1) in CSCC through regulation of microRNA (miR)-302b/c/d-3p and Cyclin O (CCNO).

Methods: The expression of RACK1, miR-302b/c/d-3p and CCNO in CSCC tissues and cells was measured by RT-qPCR and Western blot analysis. The interaction among RACK1, miR-302b/c/d-3p, and CCNO was determined by dual luciferase reporter assay. Subsequently, effects of RACK1, miR-302b/c/d-3p and CCNO on CSCC cell cycle entry, proliferation and apoptosis were investigated with the use of flow cytometry, EdU, and TUNEL assays. Furthermore, mouse xenograft model of CSCC cells was established to verify the function of RACK1 in vivo.
\end{abstract}

Results: RACK1 and miR-302b/c/d-3p were down-regulated and CCNO was overexpressed in CSCC. CCNO was identified as the target of miR-302b/c/d-3p. Importantly, overexpressed miR-302b-3p, miR-302c-3p or miR-302d-3p or RACK1 enhanced the apoptosis and suppressed the proliferation of CSCC cells in vitro, while inhibiting tumor growth in vivo by targeting CCNO.

Conclusions: On all accounts, overexpressed RACK1 could dampen the progression of CSCC through miR-302b/c/d3p-mediated CCNO inhibition.

Keywords: Cervical squamous cell carcinoma, Receptor for activated protein C kinase 1, Cyclin O, MicroRNA-302b/c/ d-3p, Apoptosis

\section{Background}

Cervical squamous cell carcinoma (CSCC) is one of the causes of cancer-related deaths in women [1]. There were 569,847 newly diagnosed cases of CSCC and 311,365 deaths reported in 2018 [2]. Notably, CSCC has been

\footnotetext{
*Correspondence: 114484715@qq.com
}

Department of Gynaecology, Affiliated Hospital of Youjiang Medical University for Nationalities, No. 18, Zhongshan Second Road, Youjiang District, Baise, Guangxi Zhuang Autonomous Region 533000, People's Republic of China proven to be the second leading cause of cancer deaths in young women (aged 20 to 39 years), which highlights that increased screening and administration of human papillomavirus (HPV) vaccination are of a high necessity in young women [3]. The therapeutic ratio of CSCC can be significantly improved via image-guided brachytherapy, as it reduces late toxicities [4]. A low pretreatment HPV viral load may indicate poor prognosis in CSCC, and the survival nomogram based on it can estimate the longterm prognosis [5].

(C) The Author(s) 2020. This article is licensed under a Creative Commons Attribution 4.0 International License, which permits use, sharing, adaptation, distribution and reproduction in any medium or format, as long as you give appropriate credit to the original author(s) and the source, provide a link to the Creative Commons licence, and indicate if changes were made. The images or other third party material in this article are included in the article's Creative Commons licence, unless indicated otherwise in a credit line to the material. If material is not included in the article's Creative Commons licence and your intended use is not permitted by statutory regulation or exceeds the permitted use, you will need to obtain permission directly from the copyright holder. To view a copy of this licence, visit http://creativeco mmons.org/licenses/by/4.0/. The Creative Commons Public Domain Dedication waiver (http://creativecommons.org/publicdomain/ zero/1.0/) applies to the data made available in this article, unless otherwise stated in a credit line to the data. 
Transcription factor AP-1 is involved in cervical cancer development [6]. Another transcription factor, homeobox D9 is also associated with malignant phenotype of cervical cancer [7]. Receptor for activated protein kinase C (RACK1), a multifunctional scaffolding protein, plays a functional role in nucleating cell signaling hubs and regulating protein activity, and is also involved the modulation of migration and invasion of tumor cells [8]. Moreover, downregulated RACK1 leads to pancreatic cancer growth and metastasis [9]. RACK1 depletions can also induce metastasis of gastric cancer (GC) by promoting the microRNA (miR)-302c/ interleukin (IL)-8 axis [10]. microRNAs (miRNAs) are endogenous non-coding RNAs, and multiple tumors have been observed to have dysregulated levels of miRNAs [11]. For instance, it is illustrated that miR-373 can promote the apoptosis of CSCC SiHa cells [12]. miR-195 has also been found to suppress proliferation of human cervical cancer cells by targeting cyclin D1 [13]. The miR-302-b/c/d has been found to exert crucial effects on a variety of biological processes, and modulates multiple pathological changes including cancer [14]. miR-302-3p has been shown to inhibit cervical cancer cell migration and invasion by directly targeting defective in cullin neddylation 1 domain containing 1 (DCUN1D1) [15]. In the current study, miR-302b/c/d$3 p$ was found to bind to the $3^{\prime}$-untranslated region (3'UTR) of Cyclin O (CCNO) mRNA and then directly targeted it. CCNO is a small gene encoding a $1053 \mathrm{bp}$ cDNA and a 350-amino-acid protein, and comprises two cyclin box folds [16]. CCNO has been identified as a novel protein of the cyclin family, and is known to be involved in the regulation of oocyte meiotic progression at different stages [17]. Its down-regulation inhibits the tumorigenicity of GC by enhancing cell apoptosis [18]. These findings led to the hypothesis that RACK1 might participate in the development of CSCC through the regulation of $\mathrm{miR}-302 \mathrm{~b} / \mathrm{c} / \mathrm{d}-3 \mathrm{p}$ and CCNO.

\section{Materials and methods Ethics statement}

This study was approved by the Ethic Committee of Affiliated Hospital of Youjiang Medical University for Nationalities and performed in strict accordance with the Declaration of Helsinki. All participants signed informed consent documentation prior to the study. Animal experiments were approved by the Institutional Animal Care and Use Committee of Affiliated Hospital of Youjiang Medical University for Nationalities with extensive efforts made to minimize animal suffering during the study.

\section{Study subjects}

Clinical CSCC samples were collected from 46 patients with CSCC who underwent hysterectomy from August 2015 to July 2016. The inclusion criteria for selection of patients were as follows: the patients did not receive chemotherapy, radiotherapy, endocrine therapy or other anti-tumor treatment before surgery; the patients were pathologically confirmed as CSCC after surgery; the patients had complete medical records and follow-up data. Patients suffering from combined diseases including combined breast cancer, ovarian cancer, severe liver and kidney dysfunction were excluded from the study. Thirty cases of normal cervical tissues were collected from patients who underwent hysterectomy for benign gynecological diseases.

\section{Cell treatment}

The CSCC cell line CasKi and the human normal cervical epithelial immortalized cell line $\mathrm{H} 8$ were purchased from the cell bank of BeNa Culture Collection (BNCC). Cells were cultured in Eagle's minimal essential medium (EMEM) supplemented with 10\% fetal bovine serum (FBS) and $1 \%$ penicillin/streptomycin at $37{ }^{\circ} \mathrm{C}$ with $5 \%$ $\mathrm{CO}_{2}$ and $95 \%$ saturated humidity. Cells at passage 3 were inoculated into a 24 -well plate at a density of $2 \times 10^{6}$ cells/ well), and cultured to grow into monolayer cells. CasKi cells were treated with following plasmids: small interfering RNA-negative control (si-NC), si-CCNO, NC-mimic, miR-302b-3p mimic, miR-302c-3p mimic, miR-302d-3p mimic, overexpression (oe)-NC, or oe-RACK1 using Lipofectamine 2,000 (Invitrogen Inc., Carlsbad, CA, USA). All plasmids were constructed by Shanghai Sangon Biotech company (Shanghai, China).

\section{Immunohistochemistry}

The prepared paraffin sections were dewaxed and hydrated. After microwave antigen retrieval using $1 \mathrm{mM}$ ethylenediaminetetraacetic acid (EDTA) ( $\mathrm{pH}$ 8.0), the sections were added with $3 \% \mathrm{H}_{2} \mathrm{O}_{2}$-methanol. Next, the sections were added with primary antibody against CCNO (ab47682, 1:500, Rabbit, Abcam, Cambridge, UK), and RACK1 (5432, 1:1000, Rabbit, Cell Signaling Technologies, Beverly, MA, USA), and incubation was carried out overnight at $4{ }^{\circ} \mathrm{C}$. Thereafter, the sections were re-probed with polymer enhancer (PV-9000, ZSGB-Bio, Beijing, China) at room temperature for 20 min. Next, the sections underwent further incubation with enzymelabeled anti-mouse/rabbit polymer (PV-9000, ZSGB-Bio, Beijing, China) at room temperature for $30 \mathrm{~min}$, and developed using 3,3'-diaminobenzidine (DAB) for $5 \mathrm{~min}$. After the development was halted by distilled water, the sections were counterstained with hematoxylin, 
differentiated and blued. The sections were conventionally hydrated, cleared and sealed. Finally, the sections were photographed and observed under an inverted microscope (CX41, Olympus, Tokyo, Japan).

\section{Reverse transcription quantitative polymerase chain reaction ( $R T-q P C R)$}

Total RNA was extracted from tissues or cells, followed by reverse transcription into complementary DNA (cDNA). Primers (Table 1) were designed and synthesized by Invitrogen (Invitrogen Inc., Carlsbad, CA, USA). With glyceraldehyde-3-phosphate dehydrogenase (GAPDH) and U6 (Invitrogen Inc., Carlsbad, CA, USA) used as internal references, RT-qPCR was carried out on an ABI 7,500 quantitative PCR instrument (Thermo Fisher Scientific Inc., Waltham, MA, USA) using the SYBR $^{\circledR}$ Premix Ex Taq ${ }^{\text {TM }}$ (Tli RNaseH Plus) kit (RR820A, Takara Holdings Inc., Kyoto, Japan). The final data were analyzed using the $2^{-\Delta \Delta \mathrm{Ct}}$ method.

\section{Western blot analysis}

Total protein was isolated from tissues or cells using radioimmunoprecipitation assay (R0010, Beijing Solarbio Science \& Technology Co., Ltd. (Beijing, China). Then the protein was separated using $10 \%$ sodium dodecyl sulfate polyacrylamide gel electrophoresis and transferred to polyvinylidene fluoride membrane. Next, the membrane was blocked with Tris-buffered saline Tween-20 (TBST) solution containing $5 \%$ bovine serum albumin (BSA), and incubated at $4{ }^{\circ} \mathrm{C}$ overnight with the diluted primary anti-rabbit antibody as follows: GAPDH (5174, 1:1000,

\section{Table 1 Primer sequences for RT-qPCR}

\begin{tabular}{|c|c|}
\hline Genes & Primer sequences $\left(5^{\prime}-3^{\prime}\right)$ \\
\hline \multirow[t]{2}{*}{ RACK1 } & F:TCTCTTTCCAGCGTGGCCATTAGA \\
\hline & R: CCTCGAAGCTGTAGAGATTCCGACAT \\
\hline \multirow[t]{2}{*}{ miR-302b-3p } & F: ATCCAGTGCGTGTCGTG \\
\hline & R:TGCTTAAGTGCTTCCATGTT \\
\hline \multirow[t]{2}{*}{ miR-302c-3p } & F: GCGTGCTTCCATGTTTCAGTGG \\
\hline & R: CAGTGCAGGGTCCGAGGTAT \\
\hline \multirow[t]{2}{*}{ miR-302d-3p } & F:TCTACTTTAACATGGAGGCACTT \\
\hline & R: TCACCAAAACATGGAAGCAC \\
\hline \multirow[t]{2}{*}{ CCNO } & F:TCTACAGACCTTCCGCGACT \\
\hline & R: GCTCTACCAGCACCTCACTT \\
\hline \multirow[t]{2}{*}{ U6 } & F: CGCTTCGGCAGCACATATACTA \\
\hline & R: CGCTTCACGAATTTGCGTGTCA \\
\hline \multirow[t]{2}{*}{ GAPDH } & F:TCATCTCTGCCCCCTCTGCTG \\
\hline & R: GCCTGCTCACCACCTTCTTG \\
\hline
\end{tabular}

$\mathrm{F}$, forward; $\mathrm{R}$, reverse; $\mathrm{RT}-\mathrm{qPCR}$, reverse transcription quantitative polymerase chain reaction; RACK1, receptor for activated protein kinase $\mathrm{C} ; \mathrm{CCNO}$, Cyclin O; GAPDH, glyceraldehyde-3-phosphate dehydrogenase
36 KD), RACK1 (5432, 1:1000, 32 KD), CCNO (ab47682, 1:1000, $40 \mathrm{KD})$, B-cell lymphoma 2 (Bcl-2) (3498, 1:1000, Rabbit, 26 KD), Cyclin D1 (2922, 1:1000, 15 KD), cleaved poly (ADP-ribose) polymerase (PARP) (\#5625, 1:1000, 89 KD), and cleaved caspase 3 (\#9664, 1:1000, 17 KD) [19]. All of the aforementioned antibodies were purchased from Cell Signaling Technology (Beverly, MA, USA), with the exception of CCNO from Abcam, Cambridge, UK. Then, the membrane was incubated with secondary antibody goat anti-rabbit immunoglobulin G (IgG) (ab150077, 1:1000, Abcam, Cambridge, UK). Lastly, the membrane was developed using enhanced chemiluminescence and analyzed using the gel image analysis software Image J.

\section{Dual luciferase reporter assay}

The synthetic $3^{\prime}$-UTR of CCNO wild type (WT) gene fragment was introduced into pMIR-reporter (Huayueyang Biotechnology Co., Ltd., Beijing China) using the endonucleases SpeI and HindIII, after which the mutant type (MUT) was designed based on the complementary sequence of 3'-UTR of CCNO WT. The target fragment was inserted into the pMIR-reporter reporter plasmid using T4 DNA ligase following restriction endonuclease digestion. The correctly sequenced luciferase reporter plasmids WT or MUT were co-transfected with miR302b/c/d-3p mimic or NC mimic into HEK293T cells. The cells were then collected and lysed after $48 \mathrm{~h}$ of transfection, after which luciferase activity was detected with the use of Glomax 20/20 luminometer fluorescence detector (Promega, Madison, WI, USA) using a luciferase assay kit (K801-200, BioVision Technologies, Exton, PA).

\section{5-Ethynyl-2'-deoxyuridine (EdU) assay}

Cells were seeded into 96-well plates at a density of $5 \times 10^{3}$ cells/well. After $6 \mathrm{~h}$, the cells were incubated with $100 \mu \mathrm{L}$ of EdU solution for $2 \mathrm{~h}$, fixed, and incubated with $2 \mathrm{mg} / \mathrm{mL}$ glycine for $5 \mathrm{~min}$. Next, the cells were incubated with $100 \mu \mathrm{L}$ penetrant for $10 \mathrm{~min}$, added with $100 \mu \mathrm{L}$ $1 \times$ Apollo staining reaction solution for $30 \mathrm{~min}$ of incubation, washed with $100 \mu \mathrm{L}$ penetrant and washed using $100 \mu \mathrm{L}$ methanol for $5 \mathrm{~min}$. Subsequently, the wells were incubated with $100 \mu \mathrm{L} 1 \times$ Hoechst 33,342 reaction solution under dark conditions for $30 \mathrm{~min}$ on a rotary shaker, after which the cells were blocked by the addition of 100 $\mu \mathrm{L}$ anti-fluorescence quenching tablets. Lastly, cells were photographed under a fluorescence microscope (Olympus FV1000, Olympus, Tokyo, Japan), and the number of cells was recorded. If the nucleus of the cell stained red, it was labeled positive and the exception to this finding were negative cells. 


\section{Flow cytometry}

Cells were centrifuged and cell pellet was resuspended in phosphate-buffered saline (PBS) to a concentration of about $1 \times 10^{5}$ cells $/ \mathrm{mL}$. Subsequently, the cells were fixed at $4{ }^{\circ} \mathrm{C}$ for $1 \mathrm{~h}$ using $1 \mathrm{~mL}$ pre-cooled $-20{ }^{\circ} \mathrm{C} 75 \%$ ethanol, and centrifuged, with the ethanol removed. The cells were subsequently added with $100 \mu \mathrm{L}$ RNase A avoiding exposure to light, subjected to water bath at $37{ }^{\circ} \mathrm{C}$ for $30 \mathrm{~min}$, added with $400 \mu \mathrm{L}$ propidium iodide (PI) and incubated at $4{ }^{\circ} \mathrm{C}$ for $30 \mathrm{~min}$. Finally, cell cycle entry was detected at $488 \mathrm{~nm}$.

\section{Terminal deoxynucleotidyl transferase-mediated dUTP-biotin nick end labeling (TUNEL) assay}

Tissues or cell slides were fixed, incubated with PBS containing $0.1 \%$ Triton X-100 on ice bath for $2 \mathrm{~min}$, permeabilized, and then incubated with TUNEL solution at $37{ }^{\circ} \mathrm{C}$ for $60 \mathrm{~min}$ avoiding exposure to light. Next, the cells were sealed with anti-fluorescence quenching liquid and observed under a fluorescence microscope at 450$500 \mathrm{~nm}$ and $515-565 \mathrm{~nm}$.

\section{Tumor xenograft in nude mice}

Thirty BALB/c female nude mice (aged 5 week, with weight of 18-21 g) purchased from Shanghai Lingchang Company (Shanghai, China) were selected and bred in the specific pathogen free environment at the animal experiment center of Affiliated Hospital of Youjiang Medical University for Nationalities before experiment. The nude mice were bred for 7 days in comfortable environment with moderate temperature, fed with aseptic food and drinking water, and an alternation of $12 \mathrm{~h}$ day and night. The lentiviral vectors of $\mathrm{NC}$ agomir, miR302b-3p agomir, miR-302c-3p agomir, miR-302d-3p agomir, oe-NC and oe-RACK1 were purchased from the Shanghai Sangon Biotech company (Shanghai, China). The lentivirus was collected and added to the CasKi cells $\left(1 \times 10^{8} \mathrm{TU} / \mathrm{mL}\right)$. Then the stably transfected CasKi cells were prepared as cell suspension $\left(5 \times 10^{6} / \mathrm{mL}\right)$ and subcutaneously injected into the right leg of nude mice. Tumor formation was observed daily. Once the tumor was evident, the long and short diameters of the tumor were measured every $5 \mathrm{~d}$. After $40 \mathrm{~d}$ of feeding, the nude mice were euthanized by the administration of anaesthesia. Then, the subcutaneous tumors were removed, photographed and weighed.

\section{Statistical analysis}

SPSS 21.0 statistical software (IBM Corp. Armonk, NY, USA) was used for data processing. The measurement data were expressed as mean \pm standard deviation. Independent sample $t$-test was used for data comparison between two groups. One-way analysis of variance
(ANOVA) was used for data comparison among multiple groups, followed by Tukey's post hoc test. Repeated measures ANOVA was used for data comparison at different time points, followed by Bonferroni's post hoc test with corrections for multiple comparisons. Pearson's correlation coefficient was used to analyze the correlation between $\mathrm{miR}-302 \mathrm{~b} / \mathrm{c} / \mathrm{d}-3 \mathrm{p}$ expression and CCNO expression. $p<0.05$ indicated a statistically significant value.

\section{Results}

CCNO is highly expressed in CSCC, and down-regulated CCNO suppresses proliferation but promotes apoptosis of CSCC cells

The GEPIA database revealed a high expression of $\mathrm{CCNO}$ in CSCC and endocervical adenocarcinoma $(p<0.05)$ (Fig. 1a). RT-qPCR and immunohistochemistry were conducted to verify the upregulation of CCNO in CSCC, and the results showed an increase in CCNO expression in clinical samples of CSCC patients (both $p<0.05$ ) (Fig. 1b, c. In addition, $\mathrm{CCNO}$ expression was evidently elevated in CSCC cell line (CasKi) $(p<0.05)$ (Fig. 1d, e).

Western blot analysis showed that downregulation of CCNO induced a marked decline in Bcl-2 and Cyclin D1 expression, while it resulted in elevated cleaved PARP and cleaved caspase 3 expression $(p<0.05)$ (Fig. 1f). Flow cytometry results showed that the number of cells arrested in the G0/G1 phase was increased and cells arrested in the $\mathrm{S}$ phase were obviously reduced in the absence of CCNO $(p<0.05)$ (Fig. 1g). EdU assay and TUNEL assay exhibited that downregulated CCNO led to decreased cell proliferation and increased cell apoptosis (both $p<0.05$ ) (Fig. $1 \mathrm{~h}, \mathrm{i}$ ). In summary, CCNO was highly expressed in CSCC, and down-regulated CCNO could promote apoptosis and inhibit proliferation of CSCC cells.

\section{CCNO is a target gene of $m i R-302 b / c / d-3 p$}

Upstream miRNAs of CCNO were predicted by RNA22, miRwalk, TargetScan, and mirDIP. Then, miR-302b-3p, miR-302c-3p and miR-302d-3p were verified to have a targeted regulatory relationship with $\mathrm{CCNO}$ (Fig. 2a). The targeted binding sites between miR-302b-3p/miR$302 \mathrm{c}-3 \mathrm{p} / \mathrm{miR}-302 \mathrm{~d}-3 \mathrm{p}$ and $\mathrm{CCNO}$ were predicted by the bioinformatics online site (Fig. 2b). Luciferase activity was decreased in cells co-transfected with miR$302 \mathrm{~b} / \mathrm{c} / \mathrm{d}-3 \mathrm{p}$ and WT-CCNO $(p<0.05)$ (Fig. 2c-e). Besides, overexpressed miR-302b/c/d-3p resulted in the significant inhibition of CCNO expression in the CasKi cells $(p<0.05)$ (Fig. 2f, g). Correlation analysis showed that there exists a negative correlation between CCNO and miR-302b-3p, miR-302c-3p and miR-302d-3p expressions in CasKi cells (Fig. $2 \mathrm{~h}-\mathrm{j}$ ). On the basis of 


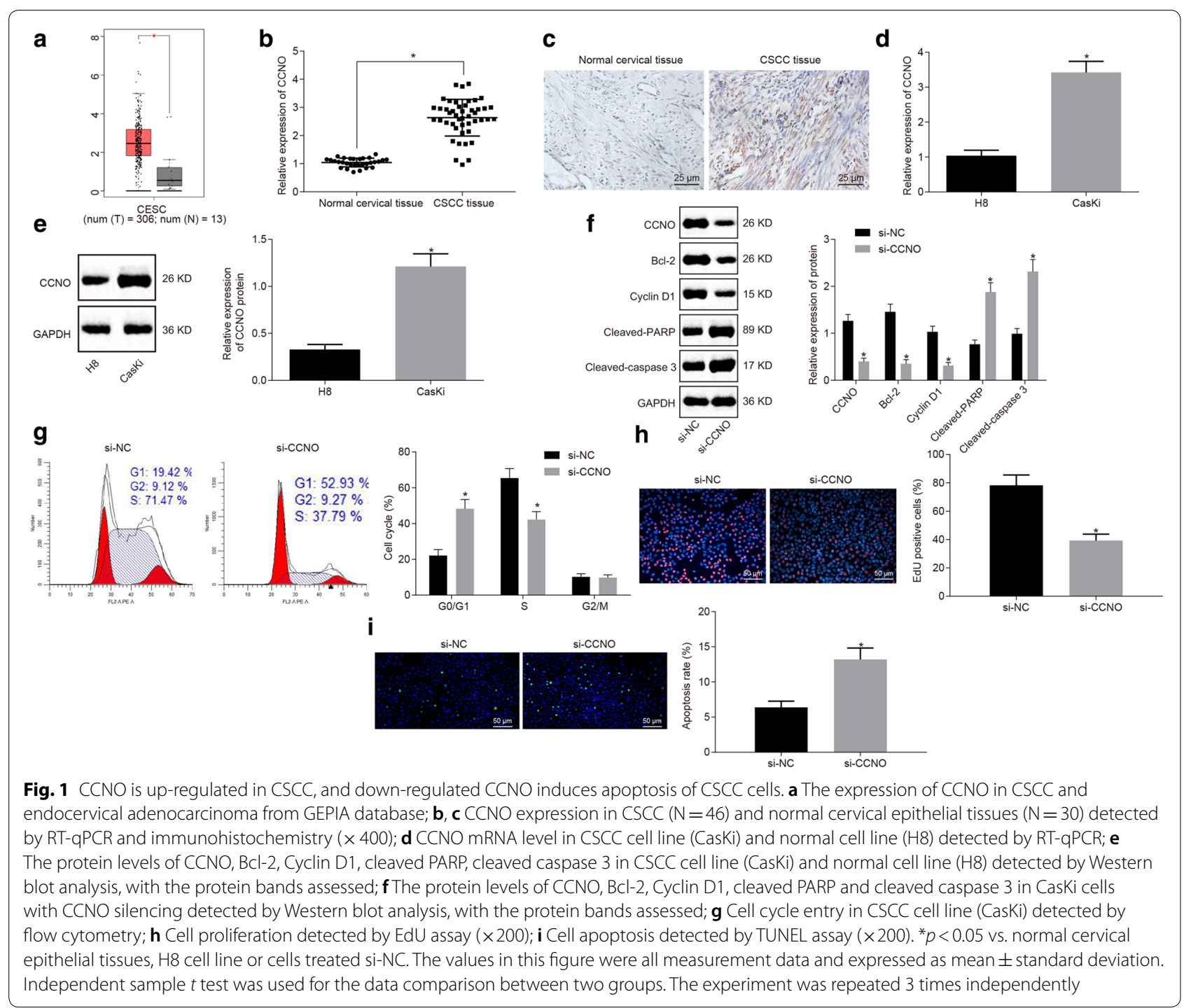

the aforementioned, $\mathrm{CCNO}$ was a target gene of miR302b-3p, miR-302c-3p and miR-302d-3p and could be negatively regulated by them.

\section{miR-302b-3p, miR-302c-3p or miR-302d-3p suppresses proliferation and enhances apoptosis of CSCC cells by downregulating CCNO}

RT-qPCR showed a decrease in miR-302b-3p, miR302c-3p and miR-302d-3p expressions in both CSCC patient tissues $(p<0.05)$ (Fig. $3 \mathrm{a}-\mathrm{c})$, and CasKi cell line $(p<0.05)$ (Fig. 3d). Then, miR-302b-3p, miR-302c-3p and miR-302d-3p were overexpressed in CSCC cell line. Western blot analysis showed that overexpressed miR302b-3p, miR-302c-3p or miR-302d-3p led to reduced CCNO, Bcl-2 and Cyclin D1 expression and elevated cleaved PARP and cleaved caspase 3 expression $(p<0.05)$ (Fig. 3e). Moreover, overexpressed miR-302b-3p,
miR-302c-3p and miR-302d-3p increased the number of cells arrested in the G0 and G1 phase, and decreased number of cells arrested in the $S$ phase by flow cytometry $(p<0.05)$ (Fig. 3f). EdU assay and TUNEL assay revealed that overexpressed miR-302b-3p, miR-302c-3p or miR302d-3p inhibited cell proliferation while promoting cell apoptosis (both $p<0.05$ ) (Fig. 3g, h). These data indicated that miR-302b-3p, miR-302c-3p or miR-302d-3p could repress CSCC cell proliferation while stimulating apoptosis via downregulation of CCNO.

miR-302b-3p, miR-302c-3p or miR-302d-3p stim ulates CSCC cell apoptosis and suppresses tumor growth by targeting CCNO in vivo

Overexpressed miR-302b-3p, miR-302c-3p or miR$302 d-3 p$ resulted in a significant decrease in size, volume and weight of subcutaneous tumors in nude mice 


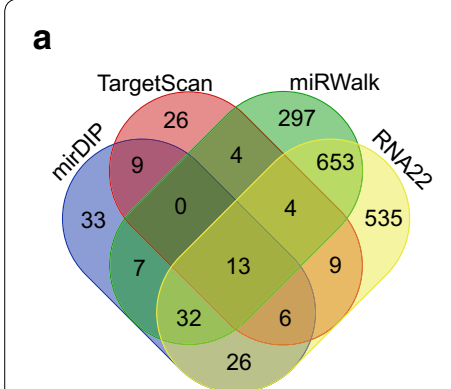

b
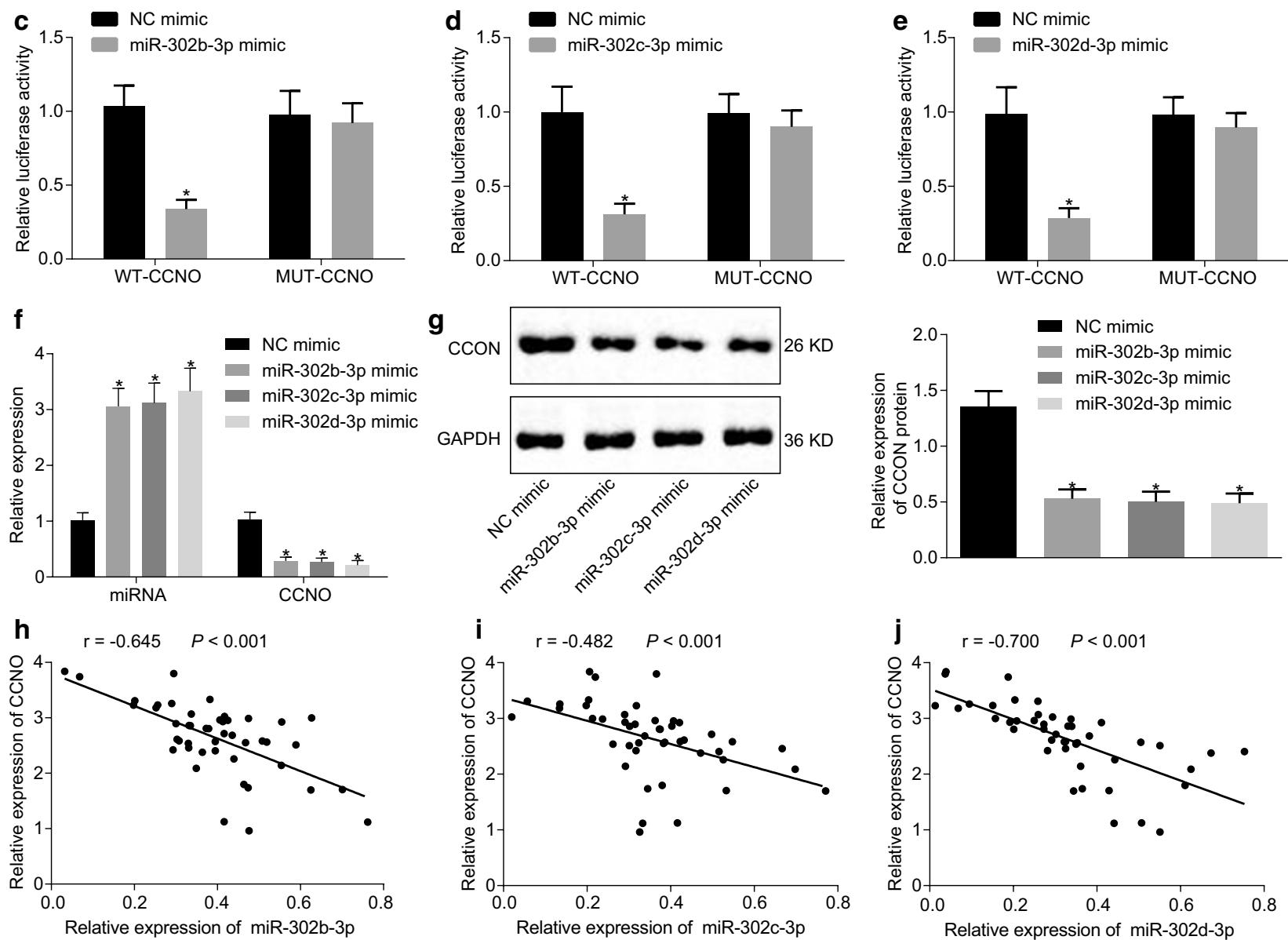

Fig. 2 miR-302b/c/d-3p targets CCNO and inhibits its expression. a The comparison of upstream miRNA of CCNO predicted by RNA22, miRwalk, TargetScan, and mirDIP; $\mathbf{b}$ The binding site between miR-302b/c/d-3p and CCNO-3'-UTR; c-e Luciferase activity in cells after transfection with miR-302b/c/d-3p and WT-CCNO or miR-302b/c/d-3p and MUT-CCNO detected by dual luciferase reporter assay; $\mathbf{f}$ The expression of miR-302b/ c/d-3p and CCNO in cells detected by RT-qPCR; $\mathbf{g}$ CCNO protein expression detected by Western blot analysis, with the protein bands assessed; $\mathbf{h}-\mathbf{j}$ Correlation analysis between CCNO expression and miR-302b/c/d-3p expression in CasKi cells. ${ }^{*} p<0.05$ vs. the cells treated with NC mimic. The values in the figure were measurement data, and expressed as mean \pm standard deviation. Independent sample $t$ test was used for data comparison between two groups. One-way ANOVA was used for data comparison among multiple groups, and followed by Tukey's post hoc test. Pearson's correlation coefficient was used for correlation analysis between indicators. The experiment was repeated 3 times independently

(Fig. 4a-c). RT-qPCR showed an increase in the expression of miR-302b-3p, miR-302c-3p or miR-302d-3p in mice following the overexpression of miR-302b-3p, miR-302c-3p or miR-302d-3p $(p<0.05)$ (Fig. $4 d)$, which was indicative of successful transfection. Western blot analysis revealed that highly-expressed miR-302b-3p, miR-302c-3p or miR-302d-3p reduced the expression of CCNO, Bcl-2, Cyclin D1, cleaved PARP and cleaved 


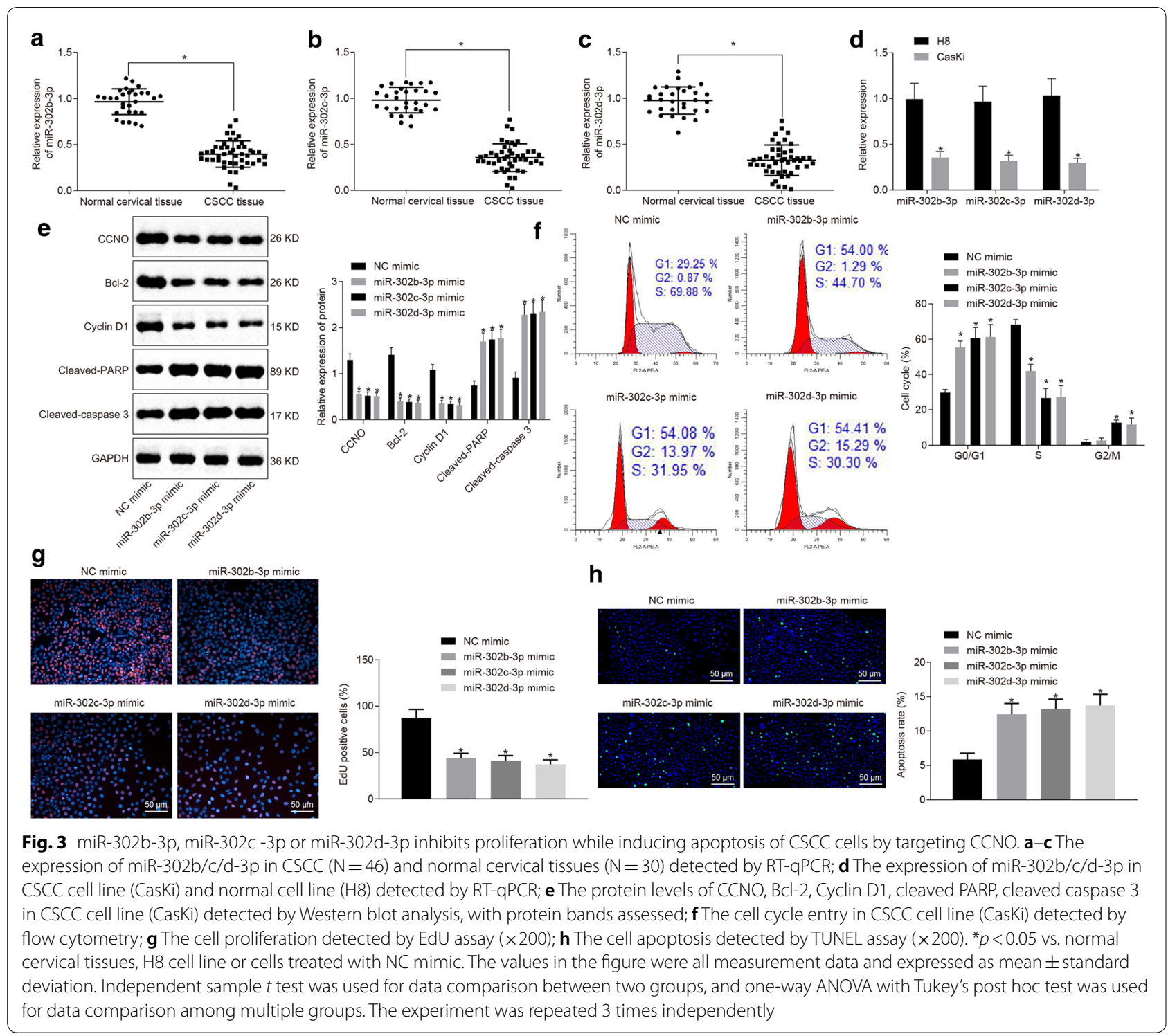

caspase 3 in subcutaneous tumors $(p<0.05)$ (Fig. 4e). The aforementioned data indicated that miR-302b-3p, miR-302c-3p or miR-302d-3p might accelerate CSCC cell apoptosis and prevent tumor growth by targeting $\mathrm{CCNO}$ in vivo.

RACK1 inhibits CCNO expression by promoting miR-302b-3p, miR-302c-3p or miR-302d-3p expression

RT-qPCR results showed that overexpressed RACK1 remarkably upregulated expressions of miR-302b-3p, miR-302c-3p or miR-302d-3p, while significantly downregulating $\mathrm{CCNO}$ expression $(p<0.05)$ (Fig. 5a). RACK1 protein level was increased and the protein level of CCNO was reduced after overexpression of RACK1 $(p<0.05)$ (Fig. 5b). Pearson's correlation coefficient exhibited a positive correlation between RACK1 expression and the expression of miR-302b-3p, miR-302c-3p or miR-302d-3p in CasKi cells $(p<0.05)$ (Fig. $5 c)$. In clinical settings, the positive expression of RACK1 protein was downregulated in CSCC patients from immunohistochemistry results (Fig. 5d). In summary, RACK1 inhibited CCNO expression by promoting expression of miR-302b-3p, miR-302c-3p or miR-302d-3p.

\section{RACK1 facilitates CSCC cell apoptosis and inhibits tumor formation in vivo in CSCC via miR-302b-3p, miR-302c-3p or miR-302d-3p-mediated CCNO inhibition}

A series of experiments were conducted to evaluate the effects of the RACK $1 / \mathrm{miR}-302 \mathrm{~b} / \mathrm{c} / \mathrm{d}-3 \mathrm{p}-\mathrm{CCNO}$ axis in CSCC cell progression as well as tumor growth. Western blot analysis results showed that overexpressed RACK1 led to a significant reduction in the expression of CCNO, 




Bcl-2 and Cyclin D1 and markedly elevated expression of RACK1, cleaved PARP, and cleaved caspase $3(p<0.05)$ (Fig. 6a).

Flow cytometry revealed that number of cells arrested in the G0 and G1 phase was increased but number of cells arrested in the $\mathrm{S}$ phase was reduced after overexpression of RACK1 $(p<0.05)$ (Fig. 6b). EdU assay and TUNEL assay depicted that overexpressed RACK1 induced markedly reduced cell proliferation and obviously elevated cell apoptosis (both $p<0.05$ ) (Fig. 6c, d).

Furthermore, tumor xenograft in nude mice exhibited a pronounced decline in size, volume and weight of subcutaneous tumors in nude mice after overexpression of RACK1 (Fig. 6e-g). RT-qPCR results showed that expression of miR-302b-3p, miR-302c-3p or miR-302d-3p was increased significantly in response to overexpressed RACK1 $(p<0.05)$ (Fig. 6h). In addition, the protein expression of CCNO, Bcl-2, and Cyclin D1 was found to be decreased, RACK1, while that of cleaved PARP, and cleaved caspase 3 was increased after overexpression of
RACK1 $(p<0.05)$ (Fig. 6I). The aforementioned findings suggested that the overexpression of RACK1 promoted CSCC cell apoptosis and suppressed tumor growth in vivo by inhibiting CCNO through regulation of miR302b-3p, miR-302c-3p or miR-302d-3p.

\section{Discussion}

Cervical cancer is the fourth leading cause of cancer-related deaths among females [2]. Squamous cell carcinomas, which arise from precursor squamous intraepithelial lesions, account for the majority of cervical carcinoma cases [20]. This study explored the underlying mechanism by which RACK1 is involved in CSCC and the findings demonstrated that RACK1 inhibited CCNO by promoting the expression of $\mathrm{miR}-302 \mathrm{~b} / \mathrm{c} / \mathrm{d}-3 \mathrm{p}$, thereby stimulating apoptosis of CSCC cells and delaying the progression of CSCC.

RACK1 has been previously found to be upregulated in cancer tissues obtained from 25 cervical 

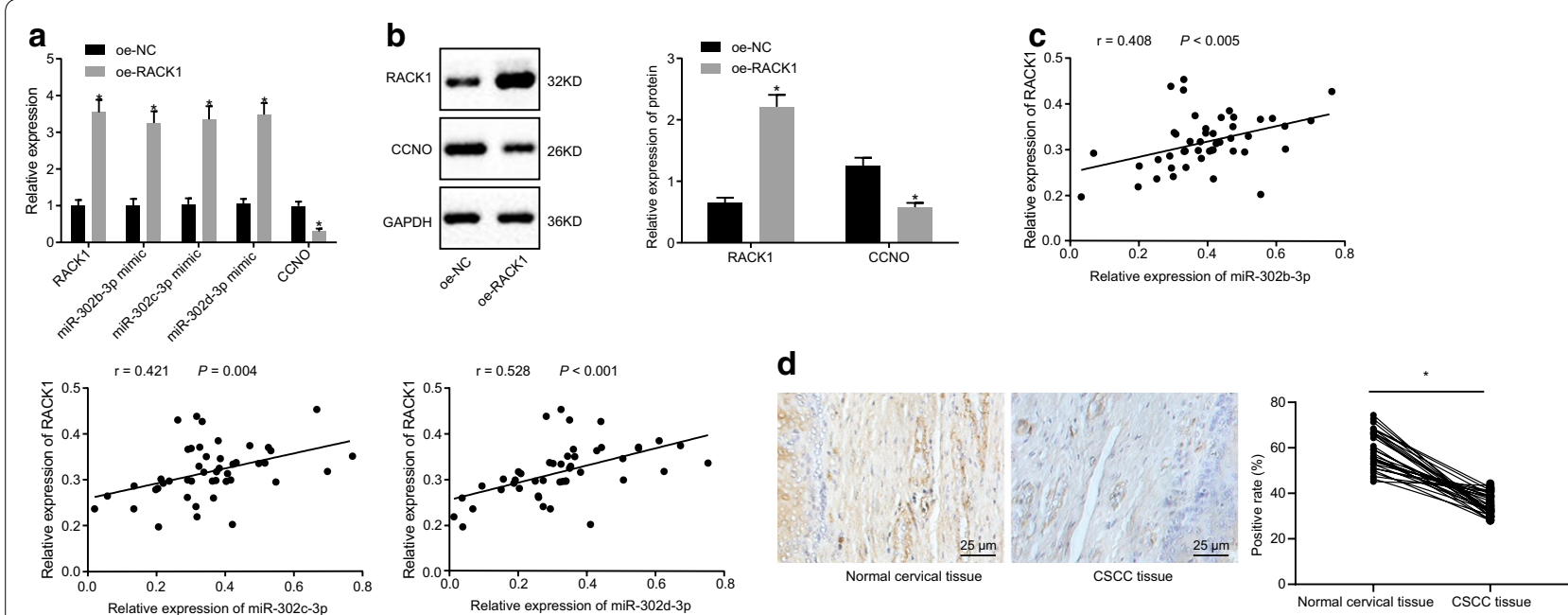

Fig. 5 RACK1 suppresses CCNO expression through enhancement of miR-302b-3p, miR-302c -3p or miR-302d-3p expression. a The expression of RACK1, miR-302b/c/d-3p, and CCNO in cells detected by RT-qPCR, ${ }^{*} p<0.05$ vs. cells treated with oe-NC; $\mathbf{b}$ Protein levels of RACK1 and CCNO examined by Western blot analysis, with protein bands assessed, ${ }^{*} p<0.05$ vs. cells treated with oe-NC; $\mathbf{c}$ The correlation between RACK 1 and miR-302b/c/d-3p in CasKi cells analyzed by Pearson's correlation coefficient; $\mathbf{d}$ Positive expression of RACK1 protein in CSCC ( $N=46)$ and normal cervical tissues $(N=30)$ detected by immunohistochemistry $(\times 400) .{ }^{*} p<0.05$ vs. cells treated with oe-NC. The values in the figure were measurement data, and expressed as mean \pm standard deviation. Independent sample $t$ test was used for data comparison between two groups. The experiment was repeated 3 times independently

cancer patients in comparison with the adjacent noncancerous tissues [21]. In addition, tissue microarray in another study revealed abundant levels of RACK1 expression in squamous intraepithelial lesion and cervical cancer [22]. However, the current study demonstrated decreased RACK1 expression in cancer tissues from the collected 46 CSCC patients compared to normal cervical tissues from 30 cases. This discrepancy may be caused by the number of the recruited study subjects and the employed controls. In addition, CSCC patients presented with down-regulated $\mathrm{miR}-302 \mathrm{~b} / \mathrm{c} / \mathrm{d}-3 \mathrm{p}$ and up-regulated CCNO. Downregulated miR-302-3p has been observed in cervical cancer tissues in comparison to adjacent normal tissues, and its low expression has been closely associated with node metastasis, advanced clinical stage, and poor prognosis in patients with cervical cancer [15]. Another study provided evidence that miR-302 directly targets another cyclin family member, Cyclin D1, and suppresses its expression, contributing to delayed tumorigenicity of endometrial cancer cells [23]. In the present study, CCNO was identified as the target of miR-302b/c/d-3p. In addition, elevated mRNA expression of CCNO has been reported in GC tissues and depletion of $\mathrm{CCNO}$ can significantly induce cancer cell apoptosis both in vitro and in vivo [18], which is partially consistent with our findings.

Our study also revealed that up-regulated RACK1 inhibited CCNO expression by promoting
miR-302b/c/d-3p expression, resulting in accelerated apoptosis in CSCC cells, as evidenced by decreased Bcl-2 and Cyclin D1 expression, and increased cleaved PARP and cleaved caspase 3 expression. RACK1 is capable of upregulating the expression of a series of miRNAs, including the miR-302 cluster, and its loss promotes GC tumor invasion and metastasis through miR-302c suppression [10]. The pro-apoptotic functions of RACK1 and its ability induce apoptosis of cells, partly by inhibiting Src have been established in a previous study [24]. Up-regulated Bcl-2 contributes to the development of laryngeal squamous cell carcinoma and inhibits cell apoptosis [25]. Cyclin D1 is associated with all cell cycle and pathologic process regulation [26]. Cyclin D1 has been proven to be capable of promoting cellular proliferation [27], and has a role in the regulation of cell migration and invasion in CSCC [28]. A previous study provided evidence that cleaved PARP-1 can serve as an apoptotic marker in the proliferative regions of the spheroids [29]. The biological role of cleaved PARP-1 includes DNA repair, maintenance of genomic integrity, modulation of transcription, replication and differentia, as illustrated in a prior study [30]. There is a study confirming that cleaved caspase 3 can be induced by Tian Xian liquid, which can inhibit tumor growth and induce apoptosis [31], suggesting that cleaved caspase 3 is positively correlated with apoptosis and inhibition of tumor expansion. miR-302 is a member of 


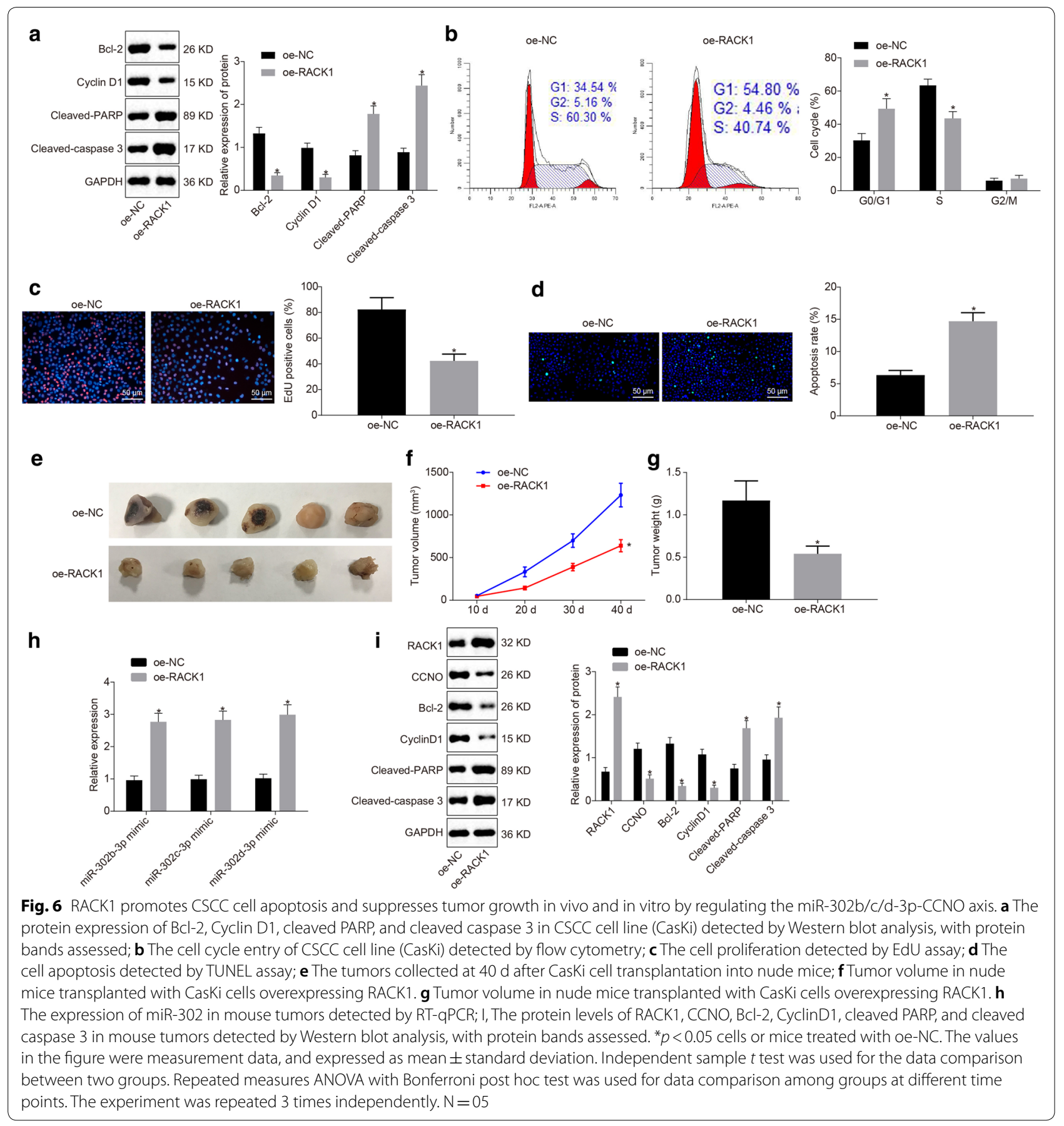

the miRNA family that regulates cancer progression and invasion via a reprogramming process, which has comprehensive effects on multiple cellular pathways and events [32]. In human endometrial carcinoma cells, miR-302b/c/d-3p has been verified to stimulate the apoptotic process [33]. These findings implicated RACK1 in CSCC through the miR-302b/c/d-3p/CCNO signaling. However, further investigations are required to elucidate the potential role of CCNO in CSCC cell migration, invasion, and lymph node metastasis in order to provide an in-depth analysis of the molecular mechanism of RACK1 in CSCC. 


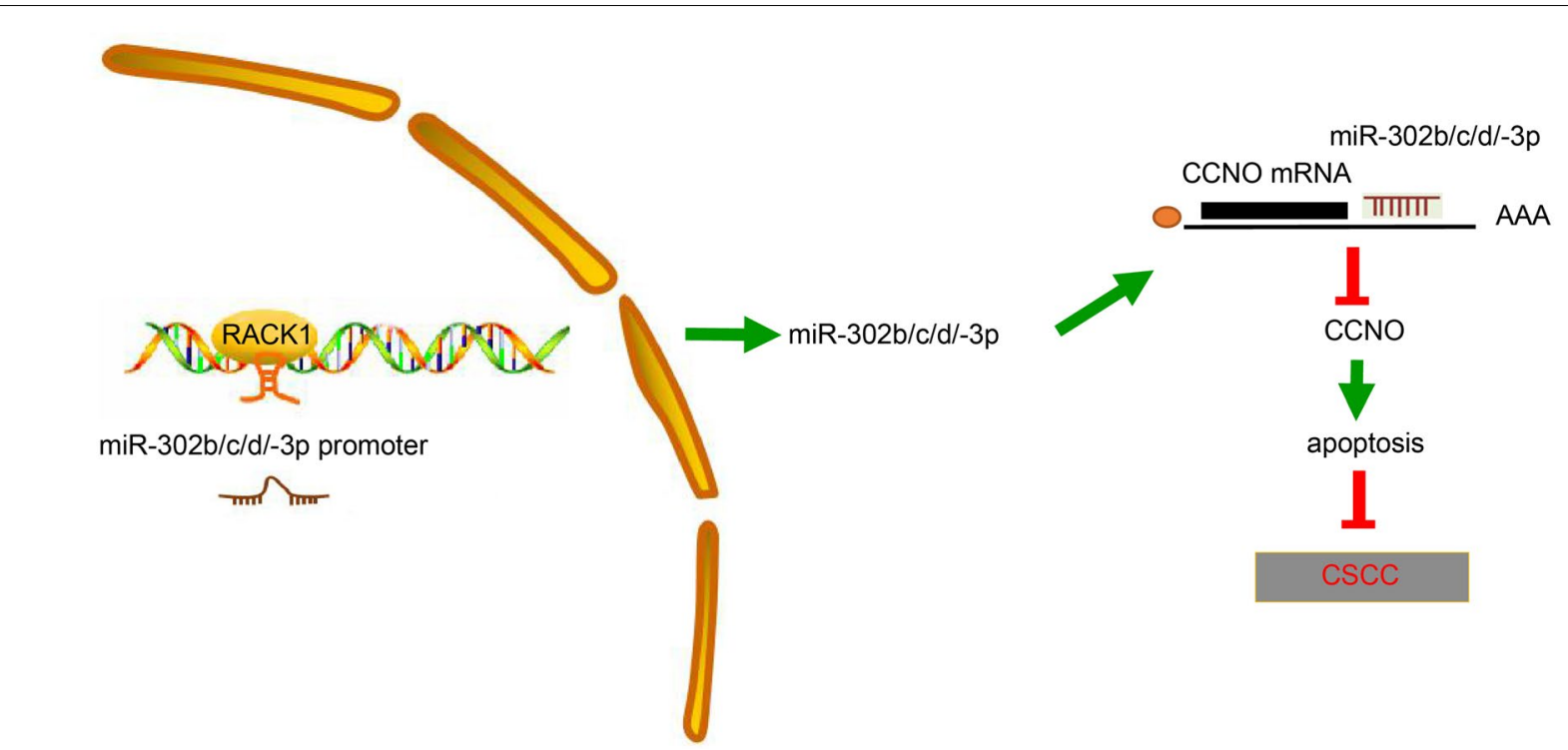

Fig. 7 A schematic of the regulatory network of RACK1 in CSCC. RACK1 enhanced miR-302b/c/d-3p expression and then inhibited CCNO expression, thereby suppressing cell apoptosis in CSCC and consequently retarding the progression of CSCC

\section{Conclusions}

In conclusion, overexpression of RACK1 could potentially enhance miR-302b/c/d-3p expression and then inhibit CCNO expression, thereby inducing cell apoptosis in CSCC and ultimately preventing the progression of CSCC (Fig. 7), which provides novel therapeutic target for CSCC. However, as this study is still in the very early stages of evaluating the specific role of RACK1 in CSCC, more studies are required to further clarify its underlying mechanism and validate its applicable value in clinical practice.

\section{Abbreviations}

CSCC: cervicalsquamous cell carcinoma; CCNO: Cyclin O; HPV: human papilIomavirus; miRNAs: microRNAs; GC: gastric cancer; RACK1IL: receptorfor activated protein kinase $C_{;}$DCUN1D1: defective in cullin neddylation 1domain containing 1; IL: interleukin; 3'-UTR: 3'-untranslated region; EMEM: Eagle's minimal essential medium; FBS: fetal bovine serum; EDTA: ethylenediaminetetraaceticacid; BNCC: BeNa Culture Collection; PARP: poly (ADP-ribose) polymerase; BCl-2: B-cell lymphoma 2; DAB: 3,3'-diaminobenzidine; BSA: bovine serum albumin; WT: wild type; MUT: mutant type; NC: negative control; Pl: propidium iodide; oe: overexpression; si: small interfering RNA; TUNEL: terminal deoxynucleotidyl transferase-mediateddUTP-biotin nick end labeling; PBS: phosphatebuffered saline; cDNA: complementary DNA; RT-qPCR: reverse transcription quantitative polymerase chainreaction; GAPDH: glyceraldehyde-3-phosphate dehydrogenase; TBST: tris-bufferedsaline with Tween-20; IgG: immunoglobulin G; EdU: 5-ethynyl-2'-deoxyuridine; ANOVA: analysis of variance.
}

\section{Acknowledgements}

The authors sincerely appreciate all members participated in this work.

\section{Authors' contributions}

JW and SCC designed the study, and were involved in data collection. JW performed the statistical analysis and preparation of Figures. SCC drafted the paper. Both authors read and approved the final manuscript.

\section{Funding}

None.

\section{Data availability statement}

The data sets used and/or analyzed during the current study are available from the corresponding author on reasonable request.

\section{Ethics approval and consent to participate}

This study was approved by the Ethic Committee of Affiliated Hospital of Youjiang Medical University for Nationalities and performed in strict accordance with the Declaration of Helsinki. All participants signed informed consent documentation prior to the study. Animal experiments were approved by the Institutional Animal Care and Use Committee of Affiliated Hospital of Youjiang Medical University for Nationalities with extensive efforts made to minimize animal suffering during the study.

\section{Consent for publication}

Consent for publication was obtained from the participants.

\section{Competing interests}

The authors declare that they have no competing interests.

Received: 14 January 2020 Accepted: 18 July 2020

Published online: 10 August 2020

\section{References}

1. Ferlay J, Soerjomataram I, Dikshit R, Eser S, Mathers C, Rebelo M, Parkin DM, Forman D, Bray F. Cancer incidence and mortality worldwide: sources, methods and major patterns in GLOBOCAN 2012. Int J Cancer. 2015;136(5):E359-86.

2. Bray F, Ferlay J, Soerjomataram I, Siegel RL, Torre LA, Jemal A. Global cancer statistics 2018: GLOBOCAN estimates of incidence and 
mortality worldwide for 36 cancers in 185 countries. CA Cancer J Clin. 2018;68(6):394-424.

3. Siegel RL, Miller KD, Jemal A. Cancer statistics. CA Cancer J Clin. 2018;68(1):7-30.

4. Chen SW, Liang JA, Hung YC, Yeh LS, Chang WC, Lin WC, Chang YY. Effectiveness of image-guided brachytherapy in patients with locally advanced cervical squamous cell carcinoma receiving concurrent chemoradiotherapy. Anticancer Res. 2019;39(6):3015-24.

5. Zuo J, Huang Y, An J, Yang X, Li N, Huang M, Wu L. Nomograms based on HPV load for predicting survival in cervical squamous cell carcinoma: an observational study with a long-term follow-up. Chin J Cancer Res. 2019;31(2):389-99.

6. Diaz-Gonzalez DM, Rodriguez-Aguilar S, Meneses-Acosta ED, Valadez-Graham A, Deas V, Gomez-Ceron J, Tavira-Montalvan C, Arizmendi-Heras CA, Ramirez-Bello A, Zurita-Ortega J. ME, et al. Transregulation of microRNA miR-21 promoter by AP-1 transcription factor in cervical cancer cells. Cancer Cell Int. 2019;19:214.

7. Hirao N, Iwata T, Tanaka K, Nishio H, Nakamura M, Morisada T, Morii K, Maruyama N, Katoh Y, Yaguchi T, et al. Transcription factor homeobox D9 is involved in the malignant phenotype of cervical cancer through direct binding to the human papillomavirus oncogene promoter. Gynecol Oncol. 2019;155:340.

8. Duff D, Long A. Roles for RACK1 in cancer cell migration and invasion. Cell Signal. 2017;35:250-5

9. Zhang L, Lv Y, Rong Y, Chen W, Fang Y, Mao W, Lou W, Jin D, Xu X. Downregulated expression of RACK1 results in pancreatic cancer growth and metastasis. Onco Targets Ther. 2019;12:1007-20.

10. Chen L, Min L, Wang X, Zhao J, Chen H, Qin J, Chen W, Shen Z, Tang Z, Gan Q, et al. Loss of RACK1 promotes metastasis of gastric cancer by inducing a miR-302C/L8 signaling loop. Cancer Res. 2015;75(18):3832-41.

11. Liang S, Tian T, Liu X, Shi H, Tang C, Yang S, Wang L, Chen S, Yu L. Microarray analysis revealed markedly differential miRNA expression profiles in cervical intraepithelial neoplasias and invasive squamous cell carcinoma. Future Oncol. 2014;10(13):2023-32.

12. Fan $L$, Liu Z, Zhang $Y$, Zhu H, Yu H, Yang F, Yang R, Wu F. MiRNA373 induces cervical squamous cell carcinoma SiHa cell apoptosis. Cancer Biomark. 2018;21(2):455-60.

13. Li Z, Wang H, Wang Z, Cai H. MiR-195 inhibits the proliferation of human cervical cancer cells by directly targeting cyclin D1. Tumour Biol. 2016;37(5):6457-63.

14. Ma G, Li Q, Dai W, Yang X, Sang A. Prognostic implications of miR-302a/b/ c/d in human gastric cancer. Pathol Oncol Res. 2017;23(4):899-905.

15. Jiang Y, Hou R, Li S, Li S, Dang G. MicroRNA-302 inhibits cell migration and invasion in cervical cancer by targeting DCUN1D1. Exp Ther Med. 2018;16(2):1000-8.

16. Amirav I, Wallmeier J, Loges NT, Menchen T, Pennekamp P, Mussaffi $H_{\text {, }}$ Abitbul R, Avital A, Bentur L, Dougherty GW, et al. Systematic analysis of CCNO variants in a defined population: implications for clinical phenotype and differential diagnosis. Hum Mutat. 2016;37(4):396-405.

17. Li J, Qian WP, Sun QY. Cyclins regulating oocyte meiotic cell cycle progressiondagger. Biol Reprod. 2019;101(5):878-81.

18. Li L, Cao Y, Zhou H, LiY, He B, Zhou X, Nie Z, Liang L, Liu Y, Ye L. Knockdown of CCNO decreases the tumorigenicity of gastric cancer by inducing apoptosis. Onco Targets Ther. 2018;11:7471-81.
19. Su T, Huang L, Zhang N, Peng S, Li X, Wei G, Zhai E, Zeng Z, Xu L. FGF14 functions as a tumor suppressor through inhibiting PI3K/AKT/mTOR pathway in colorectal cancer. J Cancer. 2020;11(4):819-25.

20. Muralidhar B, Goldstein LD, Ng G, Winder DM, Palmer RD, Gooding EL, Barbosa-Morais NL, Mukherjee G, Thorne NP, Roberts I, et al. Global microRNA profiles in cervical squamous cell carcinoma depend on Drosha expression levels. J Pathol. 2007:212(4):368-77.

21. Liao S, Xiao S, Chen H, Zhang M, Chen Z, Long Y, Gao L, He J, Ge Y, Yi W, et al. The receptor for activated protein kinase $C$ promotes cell growth, invasion and migration in cervical cancer. Int J Oncol. 2017:51(5):1497-507.

22. Wu H, Song S, Yan A, Guo X, Chang L, Xu L, Hu L, Kuang M, Liu B, He D, et al. RACK1 promotes the invasive activities and lymph node metastasis of cervical cancer via galectin-1. Cancer Lett. 2020;469:287-300.

23. Yan GJ, Yu F, Wang B, Zhou HJ, Ge QY, Su J, Hu YL, Sun HX, Ding LJ. MicroRNA miR-302 inhibits the tumorigenicity of endometrial cancer cells by suppression of Cyclin D1 and CDK1. Cancer Lett. 2014;345(1):39-47.

24. Mamidipudi V, Cartwright CA. A novel pro-apoptotic function of RACK1: suppression of Src activity in the intrinsic and Akt pathways. Oncogene. 2009;28(50):4421-33.

25. Chrysovergis A, Papanikolaou VS, Tsiambas E, Ragos V, Peschos D, Kyrodimos E. Digital Analysis of BCL2 Expression in Laryngeal Squamous Cell Carcinoma. Anticancer Res. 2019;39(3):1253-7.

26. John RR, Malathi N, Ravindran C, Anandan S. Mini review: Multifaceted role played by cyclin D1 in tumor behavior. Indian J Dent Res. 2017;28(2):187-92.

27. Fuste NP, Castelblanco E, Felip I, Santacana M, Fernandez-Hernandez R, Gatius S, Pedraza N, Pallares J, Cemeli T, Valls J, et al. Characterization of cytoplasmic cyclin D1 as a marker of invasiveness in cancer. Oncotarget. 2016;7(19):26979-91.

28. Stewart CJ, Crook ML. Cervical intraepithelial neoplasia (CIN) 3-like squamous cell carcinoma of the cervix: a review of 14 cases with comparison of E-cadherin and cyclin D1 expression in the CIN 3-like and infiltrative tumour elements. Histopathology. 2017;70(3):367-74.

29. Qvarnstrom OF, Simonsson M, Eriksson V, Turesson I, Carlsson J. gammaH2AX and cleaved PARP-1 as apoptotic markers in irradiated breast cancer BT474 cellular spheroids. Int J Oncol. 2009;35(1):41-7.

30. Bouchard VJ, Rouleau M, Poirier GG. PARP-1, a determinant of cell survival in response to DNA damage. Exp Hematol. 2003;31 (6):446-54.

31. Liu Q, Tong Y, Sze SC, Liu WK, Lam L, Chu ES, Yow CM. Tian Xian Liquid (TXL) induces apoptosis in HT-29 colon cancer cell in vitro and inhibits tumor growth in vivo. Chin Med. 2010;5:25.

32. Maadi H, Moshtaghian A, Taha MF, Mowla SJ, Kazeroonian A, Haass NK, Javeri A. Multimodal tumor suppression by miR-302 cluster in melanoma and colon cancer. Int J Biochem Cell Biol. 2016;81(Pt A):121-32.

33. Li Y, Huo J, Pan X, Wang C, Ma X. MicroRNA 302b-3p/302c-3p/302d-3p inhibits epithelial-mesenchymal transition and promotes apoptosis in human endometrial carcinoma cells. Onco Targets Ther. 2018;11:1275-84.

\section{Publisher's Note}

Springer Nature remains neutral with regard to jurisdictional claims in published maps and institutional affiliations.

Ready to submit your research? Choose BMC and benefit from:

- fast, convenient online submission

- thorough peer review by experienced researchers in your field

- rapid publication on acceptance

- support for research data, including large and complex data types

- gold Open Access which fosters wider collaboration and increased citations

- maximum visibility for your research: over $100 \mathrm{M}$ website views per year

At BMC, research is always in progress.

Learn more biomedcentral.com/submissions 